\title{
Trophic position of Antarctic ice fishes reflects food web structure along a gradient in sea ice persistence
}

\author{
Rebecca M. McMullin*, Stephen R. Wing, Lucy C. Wing, Olya A. Shatova \\ Department of Marine Science, University of Otago, PO Box 56, Dunedin 9054, New Zealand
}

\begin{abstract}
Variation in sea ice conditions is closely linked to primary production in Antarctica, which, in turn, influences food web dynamics. To investigate how sea ice dynamics are reflected in food web structure, we measured the trophic level and composition of basal organic matter supporting the prey base of 2 benthic and 2 pelagic ice fish species collected from sites along a gradient in sea ice persistence in McMurdo Sound, Ross Sea, Antarctica. Stable isotope analysis $\left(\delta^{15} \mathrm{~N}\right.$ and $\delta^{13} \mathrm{C}$ ) was carried out on samples collected from multiple sites during 2008 and 2012 to 2014 . General linear models revealed that 'trophic position' differed among species at a single site, and within benthic species among sites distributed along the gradient in sea ice persistence. Benthic species located at the southernmost sites in McMurdo Sound derived the highest proportion of diet from food webs supported by the sea ice microbial community (SIMCO), an important subsidy of organic matter to the sea-floor environment. Increased thickness and persistence of sea ice in McMurdo Sound due to the presence of icebergs resulted in a higher proportion of diet derived from SIMCO for the ice fish Trematomus bernacchii in 2008 compared to the 2012 to 2014 period. Analyses of dispersion for individual trophic positions revealed that individual level specialisation was lowest at sites with the highest variability in sea ice cover. These results provide evidence for linkages between sea ice dynamics and food web structure, and highlight the role of ice fishes as sentinels for environmental and ecological changes in Antarctica.
\end{abstract}

KEY WORDS: Ice fish $\cdot$ Stable isotopes $\cdot$ Trophic position $\cdot$ SIMCO $\cdot$ Sea ice $\cdot$ Antarctica

\section{INTRODUCTION}

As a direct consequence of sea ice cover, primary productivity varies strongly in Antarctica over relatively short distances of 15 to $40 \mathrm{~km}$ (Dayton \& Oliver 1977, Dayton et al. 1986), affecting food web structure within coastal sea-floor communities (Barry \& Dayton 1991). As a corollary, resolving how sea ice dynamics are linked with organic matter inputs to food webs is important for understanding how Antarctic marine ecosystems could be influenced by modifications to sea ice extent and persistence under environmental change (Clarke \& Harris 2003). In this context, the strong gradient in persistence of sea ice within McMurdo Sound in the Ross Sea, Antarctica, offers a valuable opportunity to study the effects of

\footnotetext{
${ }^{*}$ Corresponding author: mcmre958@student.otago.ac.nz
}

sea ice conditions on food web structure. The Sound is covered by seasonal sea ice during the winter months, with the northern portion $\left(77^{\circ} 16^{\prime} 59.4^{\prime \prime} \mathrm{S}\right.$, $166^{\circ} 25^{\prime} 41.0^{\prime \prime} \mathrm{E}$ ) being annually clear of ice by October or November due to the Cape Bird currents (Littlepage 1965, Barry \& Dayton 1988). The sea ice continues to break up through the summer months, with open water progressively moving south into the Sound. Sea ice breakup does not usually proceed to the Ross Sea ice shelf, however once every 3 to $5 \mathrm{yr}$ on average the sea ice breaks up as far south as Cape Armitage, where a consistent polynya forms in summer. The result is a predictable gradient in the persistence and thickness of sea ice cover from Cape Bird to Cape Armitage (see Fig. 1). Complete sea ice breakup may become more frequent in the Ross Sea

(C) The authors 2017. Open Access under Creative Commons by Attribution Licence. Use, distribution and reproduction are unrestricted. Authors and original publication must be credited. 
region with rising atmospheric and sea water temperatures, and changes in oceanographic circulation patterns (Thompson \& Solomon 2002, Gillett \& Thompson 2003, Schloss et al. 2012).

Both regular latitudinal shifts in physical factors such as sea ice and light regime, along with regional fluctuations controlled by oceanographic and atmospheric circulation and coastal topography are important determinants of productivity patterns in ice covered environments (Thrush et al. 2006, Dayton et al. 2016). Patterns in productivity within McMurdo Sound are strongly influenced by oceanographic circulation from the north and the persistence of sea ice, which modifies exposure to summertime light regimes and nutrient delivery at the retreating edge of the ice (Bunt 1962, Dayton \& Oliver 1977, Sullivan \& Palmisano 1984). Pelagic phytoplankton contribute the largest quantity of organic matter per year during summertime bloom events (Arrigo 2014). Alternatively, the complex sea ice microbial community (SIMCO), made up of diatoms and microbes that persist within the sea ice matrix, provides a small but stable source of organic matter for communities living beneath the sea ice through the winter months (Bunt 1962). In the coastal outer regions of McMurdo Sound, the majority of organic matter entering the benthic food web comes from pelagic phytoplankton from blooms in open water, at the edge of sea ice and in open water polynyas (Wing et al. 2012). However, at coastal sites that experience relatively persistent sea ice cover, the level of light reaching the underside of the ice is low due to ice and snow cover compared to sites experiencing long periods of open water (e.g. Dayton et al. 1986). Year-round sea ice cover severely limits primary production in these areas, leading to a low abundance of microphytes and macrophytes, and a low standing stock of phytoplankton (Dayton \& Oliver 1977). In environments where sea ice cover dominates, SIMCO provides an important alternate source of particulate flux to the benthic communities (Norkko et al. 2007, Michels et al. 2008, Wing et al. 2012).

The annual progression of sea ice break-out within McMurdo Sound is usually predictable; however, sporadic physical processes such as iceberg formation can change oceanographic conditions both locally and over 100s of kms (Massom 2003, Thrush et al. 2006). The calving of large tabular icebergs off ice shelves in the southwestern Ross Sea resulted in considerable variability in sea ice conditions within McMurdo Sound from 2001 to 2006, with the Sound not being clear of ice until 2011 (Thrush \& Cummings 2011). By preventing sea ice breakout and dispersal, icebergs can influence surface circulation, the timing and extent of polynya formation, and deep water formation (Arrigo \& van Dijken 2003). The presence of icebergs near Ross Island beginning in 2001 delayed the opening of McMurdo Sound and reduced rates of pelagic primary production within the Sound by up to $90 \%$ (Arrigo \& van Dijken 2003). In addition, increased sea ice thickness in McMurdo Sound resulting from icebergs preventing sea ice breakout had consequences for both the composition of SIMCO (Remy et al. 2008) and the benthic invertebrate community in the region (Conlan et al. 2010). Changes in sea ice regimes that arise from the presence of icebergs provide both an opportunity to study sudden shifts in productivity in ice covered regions, and a challenge when trying to determine the long-term consequences to Antarctic communities of climatedriven changes in sea ice persistence.

The connection between oceanographic processes and productivity results in spatial and temporal variations in the importance of food subsidies (Polis et al. 1997, Vetter \& Dayton 1999) and the structure of benthic and pelagic communities (Menge et al. 1997). In addition to broad-scale spatial variation in sea ice persistence, local changes in environmental characteristics including substrate type, sediment composition, longitude, latitude (a proxy for broader scale patterns in sea ice cover), and depth can also influence patterns in community diversity and abundance (Cummings et al. 2006).

A repeatable method for tracing the flow of organic matter sources within complex food webs is essential for quantifying the trophic positions of consumers at appropriate temporal and spatial scales. Stable isotope techniques, as tools for studying food web linkages, can integrate average resource use by individuals over periods of months to years, depending on the tissue type analysed (Suring \& Wing 2009, Boecklen et al. 2011), and can therefore be used to study longer term changes in diet or resource use compared to conventional diet studies (Roth \& Hobson 2000, Schmidt et al. 2006). The distinct difference in the carbon isotopic signatures of the 2 main organic matter sources in Antarctica provides an opportunity to track the organic matter fixed by SIMCO and by pelagic phytoplankton (Wada et al. 1987, Rau et al. 1989), while the nitrogen isotopic signature of a consumer can be primarily used to determine trophic level (e.g. McLeod et al. 2010).

Here, we focus on identifying differences in resource use among benthic and pelagic species of ice fishes distributed across a sea ice gradient, to test the general hypothesis that site-specific and interannual 
differences in sea ice conditions, and the associated differences in supply of organic matter sources, are important drivers of food web structure in McMurdo Sound. We predicted that sedentary benthic ice fish species would utilise a higher proportion of SIMCO relative to their pelagic counterparts, where the species of different habits co-exist. We also predicted that SIMCO would be a more important source of organic matter to benthic communities located at the southernmost sites in the Sound, while the importance of pelagic production would increase at sites with earlier and more frequent sea ice breakup. Mobile pelagic species were expected to exhibit a more homogenous array of trophic positions across the sea ice gradient due to the common exchange of individuals among populations. Lastly, we predicted that SIMCO would provide a more important source of organic matter to benthic food webs in years during which the breakout of sea ice in McMurdo Sound was inhibited by icebergs, compared to years when sea ice broke out to the Ross Sea ice shelf. Trophic positions were compared among species of contrasting habit, among populations of ice fish distributed across the gradient in sea ice persistence, and between years with contrasting sea ice regimes.

The 4 focal species of ice fish in the present study are members of the family Nototheniidae, a family of acanthopterygian fishes common to Antarctica. Two of the species (Trematomus bernacchii and T. pennellii) are benthic inhabitants (Vacchi et al. 2000). The remaining 2 species occupy positions higher in the water column: Pagothenia borchgrevinki is typically a cryopelagic species, except for older individuals which may become benthic (P. K. Dayton pers. comm.), while Trematomus newnesi is a species that has been described as being cryopelagic (Andriashev 1970), semipelagic (Richardson 1975), and both cryopelagic and benthic (Eastman \& DeVries 1982), depending on the location of study. Each of the species are known to have circum-Antarctic distributions (Eastman \& Hubold 1999), and in the context of the present study act as important food web integrators; constituting an important link between the primary consumers and top predators in the Antarctic food web. For example, T. bernacchii, T. pennellii, T. newnesi, and P. borchgrevinki each feed upon small benthic or pelagic invertebrates depending on their distribution, and in turn can be important components of the prey base for top predators such as Weddell seals Leptonychotes weddellii, emperor penguins Aptenodytes forsteri, killer whales Orcinus orca, south polar skuas Stercorarius maccormicki, and Antarctic petrels Thalassoica antarctica (Kiest 1993, La Mesa et al. 2004). Large ba- thydraconid, channichthyid, and nototheniid fish, such as the Antarctic toothfish Dissostichus mawsoni, also prey on smaller ice fish species and may experience population changes or shifts in food web position if the ice fish populations become a less reliable source of food (Gordon \& Judd 2006). The broad distribution and important trophic linkages reflected in food web integrators, such as ice fishes, identifies them as valuable sentinels for how environmental changes may impact food web diversity and stability in the Antarctic food web. To test the predictions listed above, we measured $\delta^{15} \mathrm{~N}$ and $\delta^{13} \mathrm{C}$ signatures for pelagic and benthic species of ice fishes at 10 nearshore sites in McMurdo Sound. Isotopic signatures were then incorporated into mass balance models to determine the trophic level of each fish and the contribution of different sources of organic matter to their respective food webs.

\section{MATERIALS AND METHODS}

\section{Study sites}

Samples of ice fish and the SIMCO were collected at 10 sites in McMurdo Sound that spanned a sea ice gradient extending from the head of McMurdo Sound (southernmost site) to the Sound entrance (northernmost site). Samples were collected over multiple years $(2008,2012$ to 2014), during the austral spring (Oct and Nov). Samples of suspended particulate organic matter (SPOM) were also collected during multiple years. The sites were (from north to south) Cape Bird, Cape Royds, Cape Evans, Cape Evans Wall, Little Razorback Island, Erebus Ice Tongue, Turtle Rock, McMurdo Jetty, Dayton's Wall and Cape Armitage (Fig. 1). The sea ice is more persistent at the inner sites of McMurdo Sound (e.g. McMurdo Jetty, Cape Armitage, and Dayton's Wall), breaking out only once every 3 to 5 yr on average, while sea ice cover is much more ephemeral at the outer sites, with sea ice breaking out annually (e.g. Cape Bird, Cape Royds, Cape Evans).

\section{Sample collections}

Fishing was carried out using hook and line, with artificial lures illuminated by a flashing LED at 5 to 8 holes in the ice $(20 \mathrm{~cm})$ drilled with a Jiffy ${ }^{\mathrm{TM}}$ auger at each site. The depth ranges over which benthic and pelagic fish were sampled were kept constant at 3 to $7 \mathrm{~m}$ for the pelagic species and 20 to $30 \mathrm{~m}$ for the ben- 


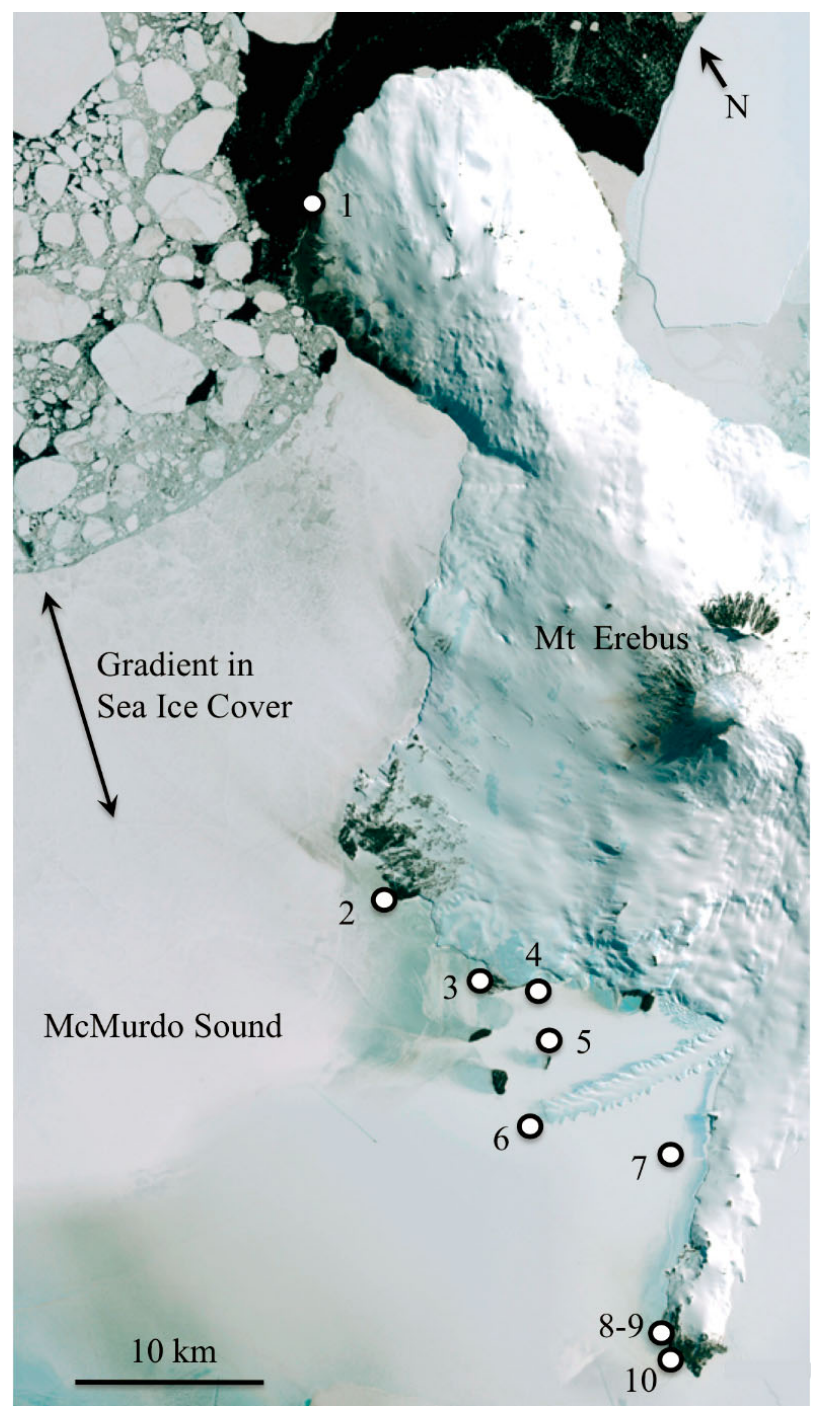

Fig. 1. Sampling sites in McMurdo Sound, Antarctica. Sites span a sea ice gradient running from the southern end of the Sound which experiences long periods of often persistent sea ice cover, to the northern end of the Sound which experiences the longest periods of open water. Site numbers: (1) Cape Bird, (2) Cape Roydes, (3) Cape Evans, (4) Cape Evans Wall, (5) Little Razorback Island, (6) Erebus Ice Tongue, (7) Turtle Rock, (8-9) McMurdo Jetty-Dayton's Wall, (10) Cape Armitage

thic species, with all sites having a bottom depth less than $30 \mathrm{~m}$, with the exception of the Erebus Ice Tongue site which had a bottom depth in excess of $150 \mathrm{~m}$. In total, 99 Trematomus bernacchii, 43 Pagothenia borchgrevinki, $39 \mathrm{~T}$. pennellii and $12 \mathrm{~T}$. newnesi were caught across the 4 sampling seasons.

The air temperature ranged between -15 and $-25^{\circ} \mathrm{C}$, resulting in the fish freezing almost immediately once removed from the water. Fish were then stored frozen until dissections were carried out at Portobello Marine Laboratory, Dunedin, New Zea- land. Each sample was thawed, blotted dry, weighed (g) and measured ( $\mathrm{mm}$ ) to obtain total wet weight and total length before dissection. Replicate samples of SIMCO were obtained from each site by taking ice cores, or by divers who collected SIMCO from the underside of the sea ice over the 4 sampling years. Samples of SPOM were collected from Cape Evans Wall, Dayton's Wall and Cape Armitage, using replicate vertical casts of a $20 \mu \mathrm{m}$ plankton net.

\section{Sample processing}

Duplicate muscle samples were taken from the dorsal musculature of each fish, behind the operculum on each side of the sagittal plane. Wet muscle tissue samples were $\geq 0.5 \mathrm{ml}$ in volume, to give a good representation of the tissue from each fish; these were placed in sterile $1.5 \mathrm{ml}$ Eppendorf tubes.

Muscle tissue was freeze-dried for $24 \mathrm{~h}$ and ground to a fine powder using a mortar and pestle. The mortar and pestle were rinsed, cleaned with ethanol, and allowed to dry between samples to prevent contamination. Sub-samples weighing $1 \mathrm{mg}$ each were taken from each ground muscle tissue sample and packaged into $3.5 \times 3 \mathrm{~mm}$ tin capsules for stable isotope analysis. Lipids were not extracted from muscle tissue before isotopic analysis as the $\mathrm{C}: \mathrm{N}$ ratio of muscle tissue ranged between 3.5 and 4.0, values which are considered borderline when determining if correction for lipids is required (Post et al. 2007, Skinner et al. 2016).

SIMCO samples were settled, decanted, and spun down into pellets to obtain enough material for isotopic analysis. In the case of core samples, the bottom 10 to $20 \mathrm{~cm}$ of the core was analysed to be consistent with samples collected by divers from the underside of the sea ice. Samples were then dried overnight at $60^{\circ} \mathrm{C}$ before being ground to a fine powder and weighed and packaged as $3 \mathrm{mg}$ sub-samples. Samples of SPOM were treated in the same manner as SIMCO samples, with the exception that low volume samples were filtered onto pre-combusted GF/F filters for isotope analysis.

Analysis of $\delta^{15} \mathrm{~N}$ and $\delta^{13} \mathrm{C}$ was carried out on a Europa 20-20 update stable isotope mass spectrometer (Europa Scientific) interfaced to a Carlo Erba elemental analyser (NA1500; Carlo Erba) in continuous flow mode (precision: $0.2 \%$ for $\delta^{13} \mathrm{C}, 0.3 \%$ for $\delta^{15} \mathrm{~N}$ ) at Iso-trace NZ in the Department of Chemistry, University of Otago. Primary standards for analysis were calibrated to EDTA laboratory standard reference (Elemental Microanalysis) and standardised against 
international standards (IAEACH-6 for C, IAEAN1 and IAEAN2 for N). The primary standard for $\delta^{15} \mathrm{~N}$ was atmospheric air, and the primary standard for $\delta^{13} \mathrm{C}$ was Vienna Pee Dee Belemnite. The isotope ratio is expressed in standard delta notation (Peterson \& Fry 1987). Variability in sample replicates within trays was estimated by calculating the average variance and standard deviation for $\delta^{15} \mathrm{~N}$ and $\delta^{13} \mathrm{C}$. As the standard deviation was less than $2 \%$ of the mean for all samples replicated within trays, we concluded that machine drift within a run was low and very unlikely to mask true differences in isotopic signatures among groups.

\section{Mixing models and estimates of trophic position}

An iterative procedure was used to determine the proportion of basal organic matter sourced from SIMCO and the trophic level of each individual (Jack \& Wing 2011). Firstly, an individual-based 2-source mass balance model (Phillips \& Gregg 2001) was used to calculate the relative contribution of SIMCO and pelagic phytoplankton using $\delta^{13} \mathrm{C}$. In this step, an initial calculation of trophic level, based on average values of $\delta^{15} \mathrm{~N}$ of the organic matter sources as $\delta^{15} \mathrm{~N}_{\text {base }}$ was used to estimate trophic discrimination of $\delta^{13} \mathrm{C}$. The results of the mass balance model were then used to refine our estimate of $\delta^{15} \mathrm{~N}_{\text {base }}$. Trophic level was then recalculated for each individual from $\delta^{15} \mathrm{~N}_{\text {base, }}$ defined as: $\left(\delta^{15} \mathrm{~N}_{\text {consumer }}-\delta^{15} \mathrm{~N}_{\text {base }}\right) / \Delta_{\mathrm{n}}$ where $\Delta_{\mathrm{n}}$ is the trophic discrimination factor, after Post (2002). The resulting estimate of trophic level was then iterated back into the mass balance model until a stable solution was obtained for both the mixture of organic matter sources and trophic level. We used the average trophic discrimination factors for aquatic environments of $+0.4 \%$ (SE: 0.17 ) for $\Delta^{13} \mathrm{C}$ and $+2.3 \%$ (SE: 0.28 ) for $\Delta^{15} \mathrm{~N}$, after McCutchan et al. (2003), for each enrichment step.

\section{Statistics}

Benthic and pelagic species of ice fish were collected from sites spanning the sea ice persistence gradient in McMurdo Sound, from locations of persistent sea ice cover in the south to locations with highly seasonal sea ice cover in the north. Collections were made in the austral springs of 2008, 2012, 2013, and 2014. This research design provided a basis for addressing the following questions: (1) Do the trophic positions of ice fishes differ among benthic and pelagic species coexisting at the same location? (2) Do the trophic positions of benthic populations and pelagic populations of ice fishes differ across the spatial gradient in sea ice persistence? (3) Does the dispersion of trophic positions in benthic and pelagic populations of ice fishes differ across the spatial gradient in sea ice persistence? (4) Does the trophic position of the benthic species $T$. bernacchii differ between 2008 and the period between 2012 and 2014, which had contrasting sea ice regimes?

\section{Trophic discrimination factors: determining the change in trophic level between ice fish and their prey}

The trophic discrimination factors for the last step of the food web (i.e. the difference between the trophic level of ice fish and their prey) were estimated so that the estimated values could be compared to the mean $\Delta^{15} \mathrm{~N}$ for aquatic food webs, reported as +2.3 (McCutchan et al. 2003). To estimate $\Delta^{15} \mathrm{~N}$ for the last step of the food web, the difference between $\delta^{15} \mathrm{~N}$ of muscle tissue and stomach contents of individual fish $\left(\delta^{15} \mathrm{~N}=\delta^{15} \mathrm{~N}_{\text {consumer }}-\delta^{15} \mathrm{~N}_{\text {diet }}\right)$ was calculated. Using the statistical software R Studio v.00.99.467, a 1-way ANOVA was applied to test for a significant difference in $\Delta^{15} \mathrm{~N}$ values among species ( $P$. borchgrevinki, T. bernacchii, $T$. newnesi, and T. pennellii).

Niche partitioning: determining how trophic position differs among co-existing species at a site

To quantify partitioning of resources among benthic and pelagic species of ice fish, we tested whether the mean trophic level or proportion of diet derived from SIMCO varied significantly among species that coexisted at a site. Linear models were fitted using the standard least squares personality in the Fit Model platform in JMP (SAS). Species was listed as an independent variable and trophic level and proportion of diet derived from SIMCO as dependent variables.

\section{Spatial variation in trophic position across the sea ice gradient}

Spatial differences in the trophic position of benthic and pelagic ice fish populations were examined by testing whether the mean trophic level or proportion of diet derived from SIMCO varied significantly among sites along the sea ice gradient. Linear mod- 
els were fitted using the standard least squares personality in the Fit Model platform in JMP. Site was set as the independent variable, and trophic level and proportion of diet derived from SIMCO were set as dependent variables. A separate analysis was run for each species (T. bernacchii, $T$, pennellii, and $P$. borchgrevinki). Pair-wise tests among sites were run using Tukey's HSD.

\section{Individual level specialisation}

Individual specialisation is a measure of the range of resources used by a population or species, and can vary with a species' habit (i.e. benthic vs. pelagic) and the environmental conditions at a location (i.e. sea ice and production regimes). To test if individual level specialisation (i.e. the dispersion of trophic positions) varied significantly along the sea ice gradient and between co-existing species, components making up trophic position were normalised, and the variability in trophic position was compared among regions/sites and among species using permutational homogeneity of dispersion (PERMDISP) in PERMANOVA+ for PRIMER v.6. This procedure uses the ANOVA F-statistic to compare distances of observations from their group centroid; p-values are obtained under permutation of least squared residuals, thereby avoiding the assumptions of normality of distribution and homogeneity of variance associated with traditional dispersion tests (Levene 1960). PERMDISP was applied to a Euclidean distance matrix using a maximum of 9999 permutations, and measuring distances from the centroid. Significant terms were tested using a posteriori pair-wise comparisons with the PERMANOVA $t$-statistic.

\section{Variation in resource use between years with contrasting sea ice regimes}

To test how annual differences in sea ice conditions in McMurdo Sound influenced the resource use of benthic ice fish, we compared the trophic position of T. bernacchii among years. Trophic positions of ice fish collected in 2008 reflect resource use in years when icebergs inhibited the breakout of sea ice in McMurdo Sound, while trophic positions of fish collected from 2012 to 2014 reflect resource use in years when sea ice broke out completely in the Sound. Linear models were fitted using the standard least squares personality in the Fit Model platform in JMP. Year was listed as an independent variable and trophic level and proportion of diet derived from SIMCO as dependent variables. Pair-wise tests among years were run using Tukey's HSD.

\section{Sensitivity analyses}

Sensitivity analyses provided a way to quantify the robustness of the isotopic mixing model to both changes in $\delta^{13} \mathrm{C}$ of organic matter sources, and to changes in $\Delta^{15} \mathrm{~N}$ used in the model. Sensitivity analyses were carried out on the Iso-Error mixing model to test the model's sensitivity to the assumed base $\delta^{13} \mathrm{C}$ values for SIMCO and SPOM, and to the amount of trophic shift resulting from the assumed level of $\Delta^{15} \mathrm{~N}$. $\delta^{13} \mathrm{C}$ data were corrected with $\pm 1 \mathrm{SE}$ and with $\pm 2 \mathrm{SE}$ from the mean base $\delta^{13} \mathrm{C}$ values for SIMCO and SPOM. $\delta^{15} \mathrm{~N}$ data were corrected with fractionation factors $\pm 10 \%$ and $\pm 20 \%$ from the mean assumed value for $\Delta^{15} \mathrm{~N}$.

\section{RESULTS}

\section{Trophic discrimination factors}

Estimates for the single step trophic discrimination factor (i.e. $\Delta^{15} \mathrm{~N}$ ), which is the difference between $\delta^{15} \mathrm{~N}$ of the ice fish and $\delta^{15} \mathrm{~N}$ of their prey, were found to range between +1.70 and $+2.21 \%$ (Table 1 ). There were no significant differences in empirically determined $\Delta^{15} \mathrm{~N}$ values among species $\left(F_{3,53}=1.26, \mathrm{p}=\right.$ 0.297).

\section{Variation in $\delta^{13} \mathrm{C}$ and $\delta^{15} \mathrm{~N}$ among species at Cape Evans Wall - evidence for niche partitioning among species}

Cape Evans Wall was the only site at which all 4 ice fish species were collected together, making it an opportune site for comparing how niche partitioning

Table 1. Mean ( $\pm 1 \mathrm{SD}$ ) trophic discrimination values for nitrogen $\left(\Delta^{15} \mathrm{~N}\right)$ for the step-wise change in isotopic signatures between ice fish and their prey

\begin{tabular}{|ll|}
\hline Species & $\Delta^{15} \mathrm{~N}( \pm 1 \mathrm{SD})$ \\
\hline Trematomus bernacchii $(\mathrm{n}=22)$ & $2.210(0.859)$ \\
Pagothenia borchgrevinki $(\mathrm{n}=13)$ & $1.697(0.869)$ \\
Trematomus pennellii $(\mathrm{n}=14)$ & $2.182(0.806)$ \\
Trematomus newnesi $(\mathrm{n}=8)$ & $2.028(0.375)$ \\
\hline
\end{tabular}


operates among these species. Fish collected from Cape Evans Wall were analysed for $\delta^{13} \mathrm{C}$ and $\delta^{15} \mathrm{~N}$ isotopes. Individual mixing models were used to estimate the trophic position of each fish (Fig. 2).

Linear models using the standard least squares method found a significant difference in the proportion of SIMCO values among species $\left(F_{3,51}=54.33\right.$, $\mathrm{p}<0.0001$ ). A post hoc Tukey's HSD test showed that significant differences existed between all species pairs with the exception of Trematomus bernacchii and T. pennellii. Linear models also found a significant difference in mean trophic level values among species $\left(F_{3,51}=42.55, \mathrm{p}<0.0001\right)$. Tukey's HSD found significant differences between the mean trophic levels of $T$. pennellii and T. newnesi, T. pennellii, and Pagothenia borchgrevinki; $T$. bernacchii and $P$. borchgrevinki; and T. bernacchii and T. newnesi. The overall results of these analyses demonstrated that benthic species occupied a higher mean trophic level, and that their prey were supported by a greater percentage of SIMCO compared to their pelagic counterparts (Fig. 2).

\section{Variation in trophic level and \% SIMCO among sites for each species}

Linear models using the standard least squares method found the mean trophic level and proportion of diet derived from SIMCO to be significantly differ-

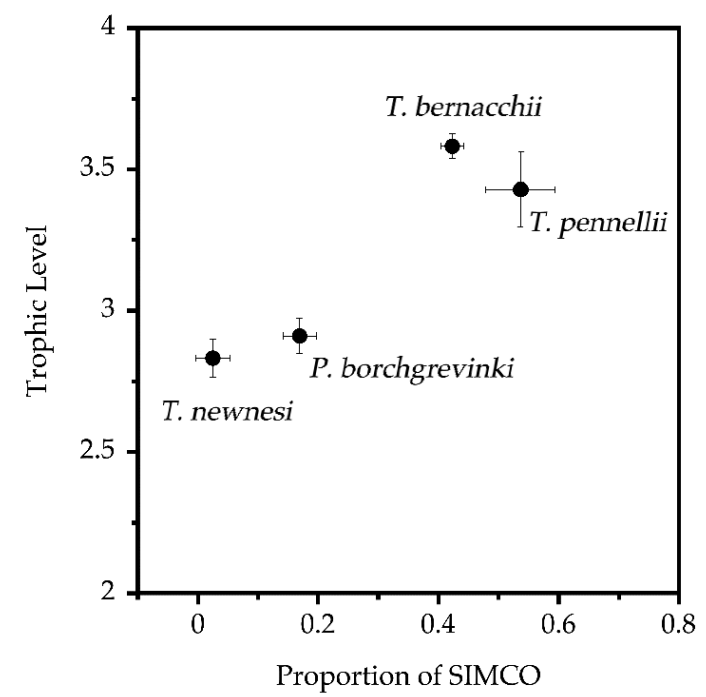

Fig. 2. Mean trophic level versus proportion of diet derived from the sea ice microbial community (SIMCO) for Trematomus bernacchii $(\mathrm{n}=27)$, Pagothenia borchgrevinki $(\mathrm{n}=13)$, $T$. pennellii $(\mathrm{n}=3)$, and $T$. newnesi $(\mathrm{n}=12)$, originating from the Cape Evans Wall site in McMurdo Sound, Antarctica. Error bars: $\pm 1 \mathrm{SE}$ ent among sites for $T$, bernacchii (trophic level: $F_{7,91}=30.40, \mathrm{p}<0.0001 ; \%$ SIMCO: $F_{7,91}=26.64, \mathrm{p}<$ 0.0001) (Fig. 3a). Pair-wise tests demonstrated a general trend for sites with more persistent sea ice cover to utilise a higher proportion of SIMCO and occupy a higher mean trophic level relative to sites that experience longer periods of open water (Fig. 3a).

Results of general linear models demonstrated that mean trophic level and the proportion of diet derived from SIMCO was significantly different among sites for T. pennellii (trophic level: $F_{6,32}=31.54, \mathrm{p}<0.0001$; $\%$ SIMCO: $F_{6,32}=18.87, \mathrm{p}<0.0001$ ) (Fig. 3b). Again, pair-wise tests showed a general trend for sites with more persistent sea ice cover to have a higher mean
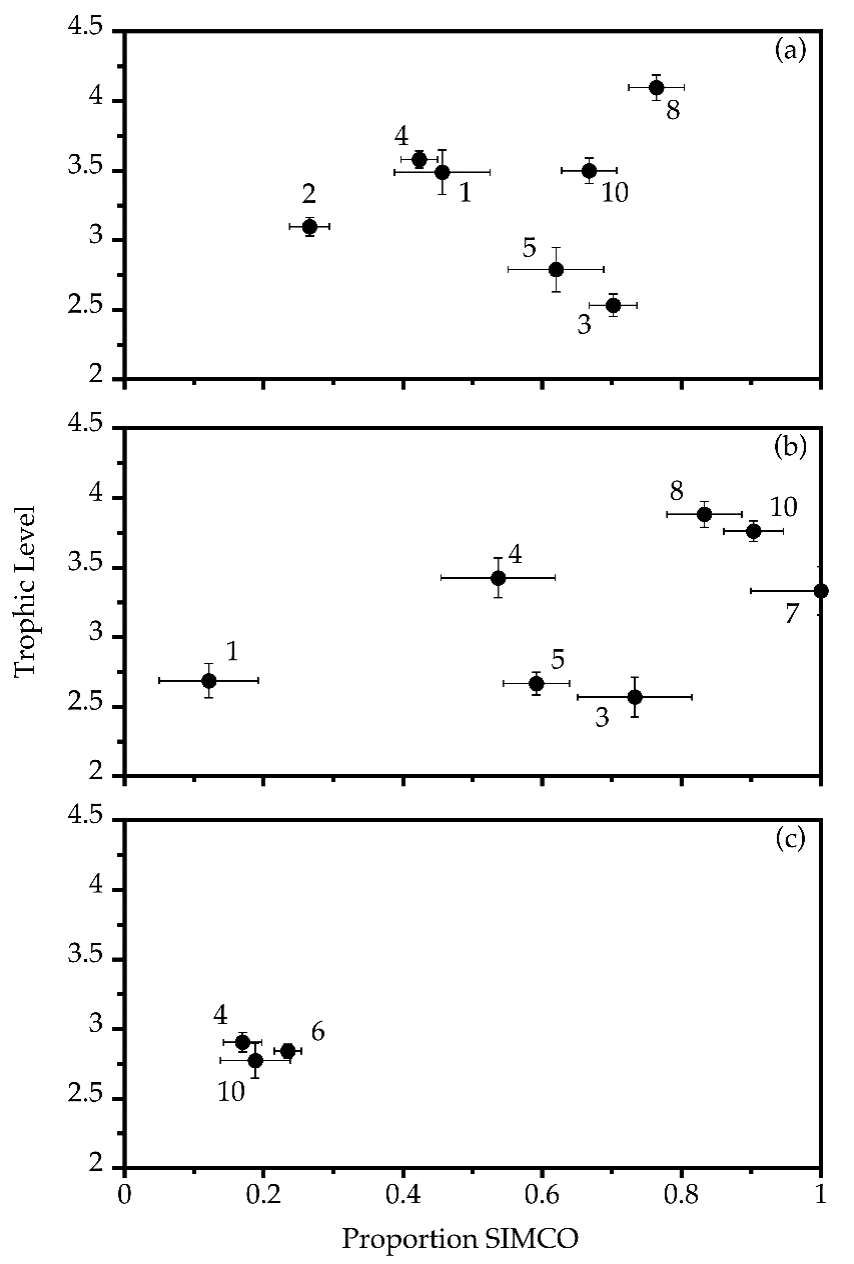

Fig. 3. Mean trophic level versus proportion of diet derived from the sea ice microbial community (SIMCO) for (a) Trematomus bernacchii $(\mathrm{n}=99)$, (b) T. pennellii $(\mathrm{n}=39)$, and (c) Pagothenia borchgrevinki $(\mathrm{n}=43)$ collected from sites spanning the sea ice gradient in McMurdo Sound, Antarctica. Error bars: \pm 1 SE. Site numbers: (1) Cape Bird, (2) Cape Royds, (3) Cape Evans, (4) Cape Evans Wall, (5) Little Razorback Island, (6) Erebus Ice Tongue, (7) Turtle Rock, (8-9) McMurdo Jetty-Dayton's Wall, (10) Cape Armitage 
trophic level and utilise a higher proportion of SIMCO (Fig. 3b). General linear models demonstrated no significant differences among sites for mean trophic level or proportion of diet derived from SIMCO for $P$. borchgrevinki (trophic level: $F_{2,40}=$ $0.51, \mathrm{p}=0.603 ; \%$ SIMCO: $F_{2,40}=1.95, \mathrm{p}=0.155$ ) (Fig. 3c).

\section{Individual level specialisation}

To test whether there were significant differences in the dispersion of trophic positions among regions or species, PERMDISP analyses were performed. The analyses comparing the dispersion of trophic positions among regions for $T$. bernacchii and $T$. pennellii were both significant (Table 2, Fig. 4), while the analysis comparing the dispersion of trophic positions among sites for $P$. borchgrevinki did not return a significant result (Table 2). A comparison of the dispersion of trophic positions among species collected at Cape Evans Wall was also found to be non-significant $\left(F_{3,51}=0.55, \mathrm{p}=0.716\right)$. Post hoc tests revealed that the dispersion of trophic positions for T. bernacchii and T. pennellii were significantly different between the inner and outer regions, and between the intermediate and outer regions of McMurdo Sound (Table 3). Dispersion in trophic positions was lowest among benthic fish collected from the outer region of McMurdo Sound (Fig. 4).

\section{Variation in trophic level and \% SIMCO among years for T. bernacchii}

Linear models using the standard least squares method found the proportion of diet derived from SIMCO to be significantly different among years for $T$. bernacchii $\left(F_{3,95}=3.13, \mathrm{p}=0.029\right)$ (Fig. 5). Pair-wise tests demonstrated that in 2008, when the breakout of sea ice from the Sound was blocked by icebergs, the proportion of diet derived from SIMCO was significantly greater compared to that in 2012, 2013 or 2014, when the sea ice broke out completely in summer
Table 2. Results of PERMDISP tests comparing dispersion of trophic positions (trophic level and \% SIMCO) among sites for Trematomus bernacchii, T. pennellii, and Pagothenia borchgrevinki. Significant results in bold

\begin{tabular}{|lrcc|}
\hline Groups & F-ratio & df & p (perm) \\
\hline Sites (T. bernacchii) & 16.96 & 2,96 & $<\mathbf{0 . 0 0 0 1}$ \\
Sites (T. pennellii) & 5.91 & 2,36 & $\mathbf{0 . 0 0 7}$ \\
Sites (P. borchgrevinki) & 0.28 & 2,40 & 0.804 \\
\hline
\end{tabular}
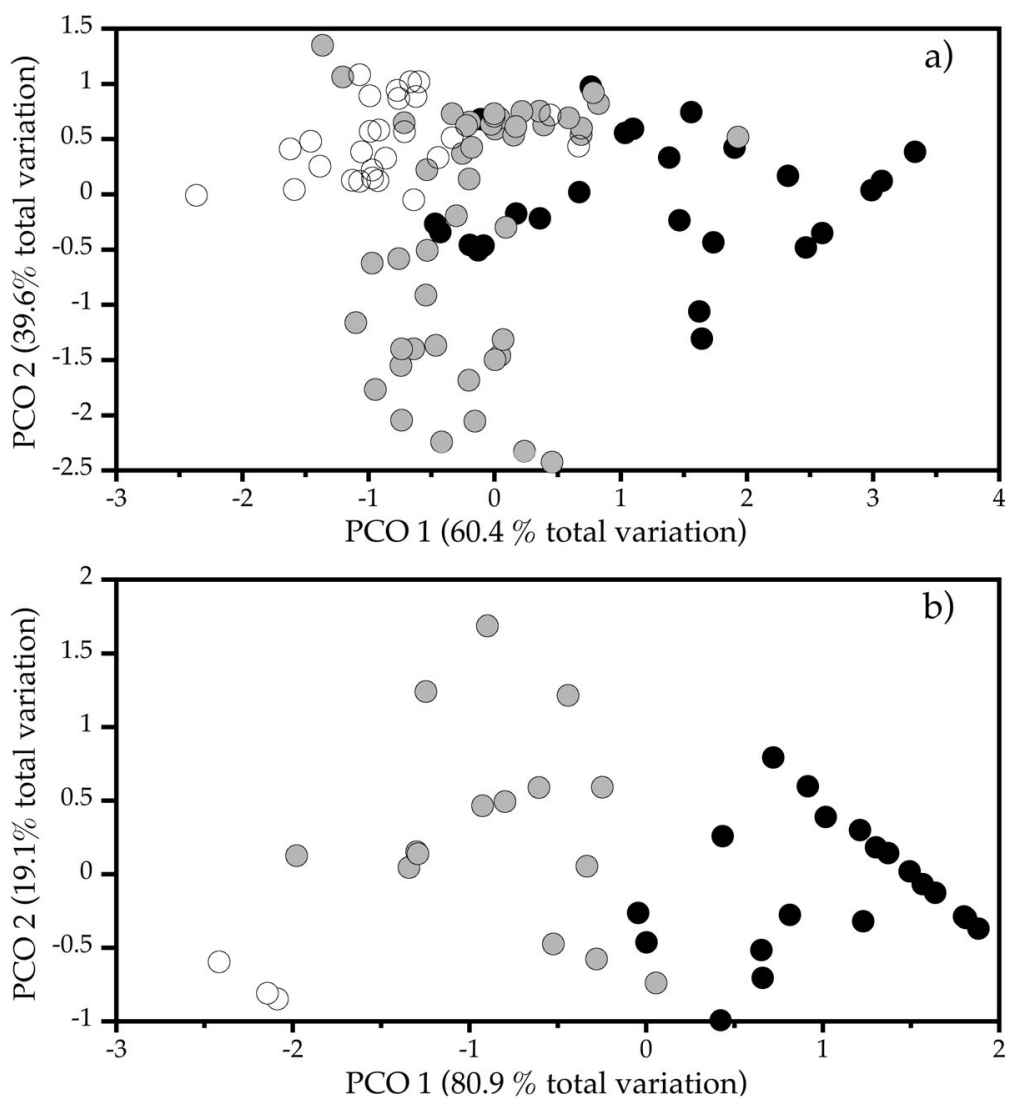

Fig. 4. Principal co-ordinates analysis (PCO) plot comparing trophic position dispersion among regions for (a) Trematomus bernacchii $(\mathrm{n}=99)$ and (b) $T$. pennellii $(\mathrm{n}=39)$. Data were normalised and based on a Euclidean distance similarity matrix. Symbols represent inner region (black circles), intermediate region (grey circles) and outer region (open circles)

Table 3. Results of PERMDISP pair-wise tests comparing dispersion of trophic positions at paired inner, intermediate, and outer sites for Trematomus bernacchii and T. pennellii. Significant results in bold

\begin{tabular}{|lcc|}
\hline Pair-wise comparisons & Pseudo-t & p (perm) \\
\hline T. bernacchii (inner), T. bernacchii (intermediate) & 0.03 & 0.976 \\
T. bernacchii (inner), T. bernacchii (outer) & 5.09 & $<\mathbf{0 . 0 0 0 1}$ \\
T. bernacchii (intermediate), T. bernacchii (outer) & 5.51 & $<\mathbf{0 . 0 0 0 1}$ \\
T. pennellii (inner), T. pennellii (intermediate) & 0.79 & 0.454 \\
T. pennellii (inner), T. pennellii (outer) & 3.81 & $\mathbf{< 0 . 0 0 1}$ \\
T. pennellii (intermediate), T. pennellii (outer) & 2.96 & $\mathbf{0 . 0 0 6}$ \\
\hline
\end{tabular}




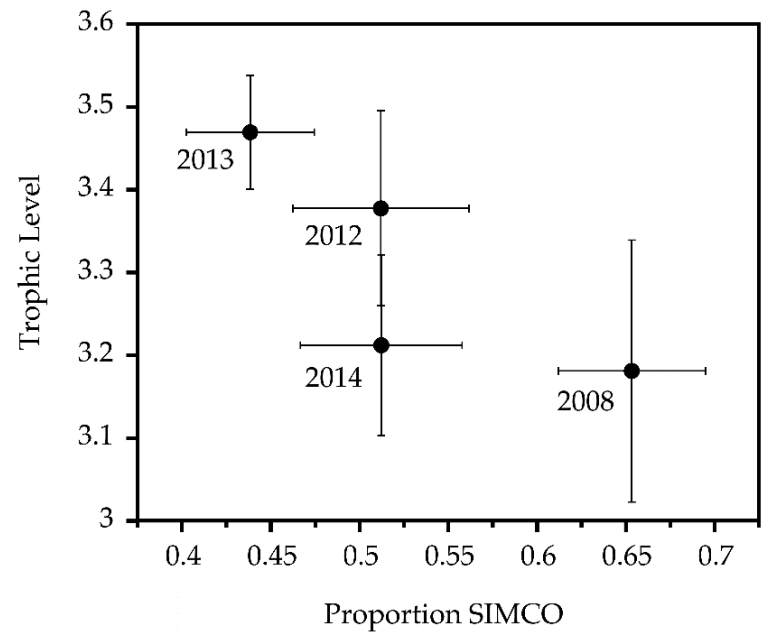

Fig. 5. Mean trophic level versus proportion of diet derived from the sea ice microbial community (SIMCO) for Trematomus bernacchii collected from McMurdo Sound, Antarctica, in $2008(\mathrm{n}=17)$ when sea ice in the Sound was blocked in by icebergs, and in $2012(\mathrm{n}=26), 2013(\mathrm{n}=25)$, and $2014(\mathrm{n}=31)$ when the Sound was ice-free in February. Error bars: $\pm 1 \mathrm{SE}$

(Fig. 5). There was no significant difference in the mean trophic level of $T$. bernacchii among years $\left(F_{3,95}=1.42, \mathrm{p}=0.243\right)$.

\section{Sensitivity analyses}

Sensitivity analysis demonstrated that the mixing models were not highly sensitive to the assumed $\delta^{13} \mathrm{C}$ values for source pools. The mean proportion of SIMCO in the diet of ice fish varied by $\sim 1.5 \%$ when the assumed base value for SIMCO was increased or decreased by 2 SE from the mean. The mean proportion of SPOM in the diet of ice fish varied by $\sim 6 \%$ when the assumed base value for SPOM was increased or decreased by 2 SE from the mean. The sensitivity model for fractionation of $\delta^{15} \mathrm{~N}$ showed how the mixing models were dependent on the assumed fractionation of $2.3 \%$ for $\Delta^{15} \mathrm{~N}$. The change from 1.92 to $2.88 \%$ fractionation resulted in an increase of approximately 1.3 trophic levels.

\section{DISCUSSION}

The data and results presented here provide strong evidence for a link between sea ice dynamics and trophic position of ice fishes in nearshore food webs in Antarctica, and for the important role of ice fishes as environmental sentinels in the Antarctic ecosystem. The mean trophic level of benthic ice fish and reliance on prey supported by the SIMCO was observed to increase with increasing sea ice persistence and thickness along the sea ice gradient. In contrast to their benthic counterparts, no significant differences were found for trophic level or the proportion of diet derived from SIMCO among sites for the pelagic species. This trend of increasing reliance on SIMCO with increasing sea ice persistence and thickness reinforces the idea that sea ice dynamics and the organic matter supplied from sea ice play important roles in the modulation of benthic food webs and the functioning of the Antarctic ecosystem.

The reliance on prey supported by SIMCO was found to be greatest for Trematomus bernacchii in 2008, when sea ice in McMurdo Sound was blocked from the open ocean by large icebergs. The presence of the icebergs altered oceanographic patterns and impaired the breakup of sea ice in the Sound (Thrush \& Cummings 2011). Increased reliance on SIMCO by benthic species likely signals a decrease in water column productivity with thick and persistent sea ice. This finding is consistent with those of Thrush \& Cummings (2011), who found mainly negative changes in benthic species abundance and community composition during years when sea ice persistence was increased by the presence of icebergs. The trophic level of T. bernacchii was lowest in 2008, and although this result was not significant, it may reflect reduced food supply to benthic communities under the 2008 sea ice regime. These results highlight the importance of resolving dynamics of food webs for forecasting how climate change may affect nearshore ecosystems in Antarctica.

Cape Evans Wall was the only site from which all 4 species of ice fish were found in close proximity, affording a unique opportunity to investigate the structure of pelagic versus benthic food webs in habitats directly adjacent to each other. We were able to compare trophic positions of the pelagic and benthic species in terms of their niche partitioning and the dispersion of isotopic signatures, which are indicative of the degree of specialisation among individuals contributing to niche breadth. Benthic fishes ( $T$. bernacchii and T. pennellii) at Cape Evans Wall utilised prey within food webs fuelled by SIMCO considerably more within each trophic level grouping compared with the pelagic species ( $T$. newnesi and Pagothenia borchgrevinki), which fed on prey from food webs that sourced a higher proportion of their basal organic matter from pelagic phytoplankton. The estimated mean trophic levels for T. bernacchii and $T$. pennellii were also significantly higher than for their pelagic counterparts. The presence of 
omnivorous consumers at high trophic levels can increase the number of ephemeral links between prey and consumers (De Angelis 1975); therefore, the higher trophic levels observed in these benthic consumers was likely a reflection of a complex benthic food web, relative to the lower trophic level prey in the pelagic food web. The benthic habitat in Antarctica offers many more micro-niches for inhabitants compared to the pelagic habitat. Benthic species have diversified to fill these niches, leading to a larger number of predator-prey interactions and a greater diversity in the prey available to consumers (Kondoh 2003).

Estimating appropriate $\Delta^{15} \mathrm{~N}$ values is a central issue when it comes to using mixing models for diet reconstruction or estimates of trophic position from stable isotope analysis (Vanderklift \& Ponsard 2003). Trophic enrichment factors (TEFs) have been calculated for many taxa, and while the mean $\Delta^{15} \mathrm{~N}$ for aquatic food webs averages around +2.3 (McCutchan et al. 2003), the range of $\Delta^{15} \mathrm{~N}$ varies with the biochemical mode of excretion and diet C: $\mathrm{N}$ ratios (Vanderklift \& Ponsard 2003). Results presented here suggest that the trophic enrichment of nitrogen in Antarctic food webs may be slightly lower than the value McCutchan et al. (2003) reported for aquatic organisms. The unique cold-adapted physiology of Antarctic species, or a switch in feeding rates over winter months, may influence TEFs in Antarctic food webs (Hobson et al. 1993, Olive et al. 2003).

Analysing the dispersion of trophic levels and composition of basal organic matter supporting the diet among individual ice fish provided a means to quantify individual level specialisation within populations as an indicator of niche breadth. Both components of trophic position - trophic level and composition of organic matter-are closely linked measures of resource use (Jack \& Wing 2011). The dispersion of trophic positions in multivariate space was significantly different among regions for $T$. bernacchii and T. pennellii. Trophic positions for these 2 benthic species had greater variability, i.e. higher dispersion, at sites located in the inner and intermediate regions of McMurdo Sound, compared to sites located in the outer region of the Sound.

Greater individual-level specialisation can be used to achieve niche expansion when interspecific competition is intense under resource limitation, or when microhabitats in which to specialise are more abundant (Bolnick et al. 2003). Our results suggest that populations of benthic ice fish from sites located further inside McMurdo Sound have a greater degree of individual specialisation than populations from areas that are regularly free of sea ice. The greater duration of sea ice cover at inner and intermediate sites within McMurdo Sound results in lower but more consistent levels of productivity, provided by SIMCO, and may result in more complex communities of prey for ice fishes at these sites. These patterns are reflected in the greater degree of individual level specialisation, higher proportion of organic matter from SIMCO, and a wider niche breadth within benthic ice fish populations under persistent sea ice cover.

In contrast, the dispersion of trophic positions in multivariate space was not found to be significantly different among sites for the pelagic species $P$. borchgrevinki. This result is consistent with a pelagic mode of life, with fish populations being highly mobile, encountering a range of sites, and having similar opportunities for niche specialisation. Individual-level variations can strongly affect a population's ecological and evolutionary dynamics, and the study of this niche metric will further our understanding of the factors that likely influence the abundance and distribution of ice fish at the regional scale in McMurdo Sound, and throughout Antarctica (e.g. Bolnick et al. 2003).

Our results highlight how different ice fish species play specific roles in routing of organic matter through nearshore food webs in Antarctica. As useful food web sentinels, studying the patterns of resource use by ice fish in Antarctic food webs can provide insight into how physical changes to the environment, such as those associated with sea ice thickness and persistence, may impact the structure and function of the Antarctic marine ecosystem. These findings have important implications for the management and conservation of species under ice-covered seas, and for understanding how climate change may affect species that specifically rely upon the sea ice environment as a source of organic matter.

Acknowledgements. We thank S. Genovese, D. Stokes, J. Leichter and M. Brunton for their assistance with field work. We are also grateful to the Isotrace research group, in the Department of Chemistry, who carried out stable isotope analysis on samples used in the research presented here. Logistic and monetary support was provided by Antarctica New Zealand, New Zealand Federation of Graduate Women the University of Otago Graduate Research School and the Royal Society of New Zealand's Marsden Fund (UOO1008).

\section{LITERATURE CITED}

Andriashev AP (1970) Cryopelagic fishes of the Arctic and Antarctic and their significance in polar ecosystems. In: Holdgate MW (ed) Antarctic ecology, Vol. 1. Academic Press, New York, p 297-304 
Arrigo KR (2014) Sea ice ecosystems. Annu Rev Mar Sci 6: 439-467

Arrigo KR, van Dijken GL (2003) Impact of iceberg C-19 on Ross Sea primary production. Geophys Res Lett 30:1836

Barry JP, Dayton PK (1988) Current patterns in McMurdo Sound, Antarctica and their relationship to local biotic communities. Polar Biol 8:367-376

Barry JP, Dayton PK (1991) Physical heterogeneity and the organization of marine communities. In: Kolasa J, Pickett $\mathrm{S}$ (eds) Ecological studies. Springer, New York, NY, p 270-320

Boecklen WJ, Yarnes CT, Cook BA, James AC (2011) On the use of stable isotopes in trophic ecology. Annu Rev Ecol Evol Syst 42:411-440

Bolnick DI, Svanbäck R, Fordyce JA, Yang LH, Davis JM, Hulsey CD, Forister ML (2003) The ecology of individuals: incidence and implications of individual specialization. Am Nat 161:1-28

Bunt JS (1962) Primary productivity under sea ice in Antarctic waters 1. Concentrations and photosynthetic activities of microalgae in the waters of McMurdo Sound, Antarctica. Antarct Res Ser 1:13-26

* Clarke A, Harris CM (2003) Polar marine ecosystems: major threats and future change. Environ Conserv 30:1-25

Conlan KE, Kim SL, Thurber AR, Hendrycks E (2010) Benthic changes at McMurdo Station, Antarctica following local sewage treatment and regional iceberg-mediated productivity decline. Mar Pollut Bull 60:419-432

Cummings V, Thrush S, Norkko A, Andrew N, Hewitt J, Funnell G, Schwarz AM (2006) Accounting for local scale variability in benthos: implications for future assessments of latitudinal trends in the coastal Ross Sea. Antarct Sci 18:633-644

Dayton PK, Oliver JS (1977) Antarctic soft-bottom benthos in oligotrophic and eutrophic environments. Science 197: 55-58

* Dayton PK, Watson D, Palmisano A, Barry JP, Oliver JS, Rivera D (1986) Distribution patterns of benthic microalgal standing stock at McMurdo Sound, Antarctica. Polar Biol 6:207-213

Dayton PK, Hammerstrom K, Jarrell SC, Kim S, Nordhausen W, Osborne DJ, Thrush SF (2016) Unusual coastal flood impacts in Salmon Valley, McMurdo Sound, Antarctica. Antarct Sci 28:269-275

De Angelis DL (1975) Stability and connectance in food web models. Ecology 56:238-243

Eastman JT, DeVries AL (1982) Buoyancy studies of notothenioid fishes in McMurdo Sound, Antarctica. Copeia 1982:385-393

Eastman JT, Hubold G (1999) The fish fauna of the Ross Sea, Antarctica. Antarct Sci 11:293-304

Gillett NP, Thompson DWJ (2003) Simulation of recent Southern Hemisphere climate change. Science 302:273-275

Gordon D, Judd W (2006) The Ross Sea toothfish fishery. In: New Zealand Geographic, Issue 79. Kowhai Media, Auckland, p 16-20

Hobson KA, Alisauskas RT, Clark RG (1993) Stable-nitrogen isotope enrichment in avian tissues due to fasting and nutritional stress: implications for isotopic analyses of diet. Condor 95:388-394

Jack L, Wing SR (2011) Individual variability in trophic position and diet of a marine omnivore is linked to kelp bed habitat. Mar Ecol Prog Ser 443:129-139

Kiest KA (1993) A relationship of diet to prey abundance and the foraging behavior of Trematomus bernacchii. Polar
Biol 13:291-296

Kondoh M (2003) Foraging adaptation and the relationship between food-web complexity and stability. Science 299: 1388-1391

*La Mesa M, Dalú M, Vacchi M (2004) Trophic ecology of the emerald notothen Trematomus bernacchii (Pisces, Nototheniidae) from Terra Nova Bay, Ross Sea, Antarctica. Polar Biol 27:721-728

Levene H (1960) Robust tests for equality of variances. In: Madow WG, Mann HB, Levene H, Olkin I, Ghurye HG, Hoeffding W (eds) Contributions to probability and statistics: essays in honor of Harold Hotelling. Stanford University Press, Stanford, CA, p 278-292

Littlepage JL (1965) Oceanographic investigations in McMurdo Sound, Antarctica. In: Llano G (ed) Biology of the Antarctic Seas II. American Geophysical Union, Washington, DC, p 1-37

Massom RA (2003) Recent iceberg calving events in the Ninnis Glacier region, East Antarctica. Antarct Sci 15: 303-313

McCutchan JH, Lewis WM, Kendall C, Mcgrath CC (2003) Variation in trophic shift for stable isotope ratios of carbon, nitrogen, and sulfur. Oikos 102:378-390

McLeod RJ, Wing SR, Davis JP (2010) Habitat conversion and species loss alters the composition of carbon sources to benthic communities. Mar Ecol Prog Ser 411:127-136

*Menge BA, Daley BA, Wheeler PA, Dahlhoff E, Sanford E, Strub PT (1997) Benthic-pelagic links and rocky intertidal communities: Bottom-up effects on top-down control? Proc Natl Acad Sci USA 94:14530-14535

Michels J, Dieckmann GS, Thomas DN, Schnack-Schiel SB and others (2008) Short-term biogenic particle flux under late spring sea ice in the western Weddell Sea. Deep Sea Res II 55:1024-1039

Norkko A, Thrush SF, Cummings VJ, Gibbs MM, Andrew NL, Norkko J, Schwarz AM (2007) Trophic structure of coastal Antarctic food webs associated with changes in sea ice and food supply. Ecology 88:2810-2820

* Olive PJW, Pinnegar JK, Polunin NVC, Richards G, Welch R (2003) Isotopic trophic-step fractionation: a dynamic equilibrium model. J Anim Ecol 72:608-617

Peterson BJ, Fry B (1987) Stable isotopes in ecosystem studies. Annu Rev Ecol Syst 18:293-320

*Phillips DL, Gregg JW (2001) Uncertainty in source partitioning using stable isotopes. Oecologia 127:171-179

*Polis GA, Anderson WB, Holt RD (1997) Toward an integration of landscape and food web ecology: the dynamics of spatially subsidized food webs. Annu Rev Ecol Syst 28: 289-316

Post DM (2002) Using stable isotopes to estimate trophic position: models, methods, and assumptions. Ecology 83 : 703-718

* Post DM, Layman CA, Arrington DA, Takimoto G, Quattrochi J, Montaña CG (2007) Getting to the fat of the matter: models, methods and assumptions for dealing with lipids in stable isotope analyses. Oecologia 152:179-189

Rau GH, Takahashi T, Des Marais DJ (1989) Latitudinal variations in plankton $\delta^{13} \mathrm{C}$ : implications for $\mathrm{CO}_{2}$ and productivity in past oceans. Nature 341:516-518

* Remy JP, Becquevort S, Haskell TG, Tison JL (2008) Impact of the B-15 iceberg 'stranding event' on the physical and biological properties of sea ice in McMurdo Sound, Ross Sea, Antarctica. Antarct Sci 20:593-604

Richardson MG (1975) The dietary composition of some Antarctic fish. Br Antarct Surv Bull 41 \& 42:113-120 
Roth JD, Hobson KA (2000) Stable carbon and nitrogen isotopic fractionation between diet and tissue of captive red fox: implications for dietary reconstruction. Can J Zool 78:848-852

Schloss I, Abele D, Moreau S, Demers S, Bers V, González O, Gustavo F (2012) Response of phytoplankton dynamics to 19-year (1991-2009) climate trends in Potter Cove (Antarctica). J Mar Syst 92:53-66

Schmidt K, Atkinson A, Petzke KJ, Voss M, Pond DW (2006) Protozoans as a food source for Antarctic krill, Euphausia superba: complementary insights from stomach content, fatty acids, and stable isotopes. Limnol Oceanogr 51: 2409-2427

Skinner MM, Martin AA, Moore BC (2016) Is lipid correction necessary in the stable isotope analysis of fish tissues? Rapid Commun Mass Spectrom 30:881-889

Sullivan CW, Palmisano AC (1984) Sea ice microbial communities: distribution, abundance, and diversity of ice bacteria in McMurdo Sound, Antarctica, in 1980. Appl Environ Microbiol 47:788-795

Suring E, Wing SR (2009) Isotopic turnover rate and fractionation in multiple tissues of red rock lobster (Jasus edwardsii) and blue cod (Parapercis colias): consequences for ecological studies. J Exp Mar Biol Ecol 370:56-63

Thompson DWJ, Solomon S (2002) Interpretation of recent Southern Hemisphere climate change. Science 296: 895-899

Editorial responsibility: Charles Peterson, Morehead City, North Carolina, USA
Thrush SF, Cummings VJ (2011) Massive icebergs, alteration in primary food resources and change in benthic communities at Cape Evans, Antarctica. Mar Ecol (Berl) 32:289-299

Thrush S, Dayton P, Cattaneo-Vietti R, Chiantore M and others (2006) Broad-scale factors influencing the biodiversity of coastal benthic communities of the Ross Sea. Deep Sea Res II 53:959-971

Vacchi M, La Mesa M, Greco S (2000) The coastal fish fauna of Terra Nova Bay, Ross Sea (Antarctica). In: Faranda FM (ed) Ross Sea ecology. Springer, Berlin, p 457-468

Vanderklift MA, Ponsard S (2003) Sources of variation in consumer-diet $\delta^{15} \mathrm{~N}$ enrichment: a meta-analysis. Oecologia 136:169-182

*Vetter EW, Dayton PK (1999) Organic enrichment by macrophyte detritus, and abundance patterns of megafaunal populations in submarine canyons. Mar Ecol Prog Ser 186:137-148

* Wada E, Terazaki M, Kabaya Y, Nemoto T (1987) ${ }^{15} \mathrm{~N}$ and ${ }^{13} \mathrm{C}$ abundances in the Antarctic Ocean with emphasis on the biogeochemical structure of the food web. Deep-Sea Res 34:829-841

*Wing SR, McLeod RJ, Leichter JJ, Frew RD, Lamare MD (2012) Sea ice microbial production supports Ross Sea benthic communities: influence of a small but stable subsidy. Ecology 93:314-323

Submitted: November 7, 2016; Accepted: December 7, 2016 Proofs received from author(s): January 26, 2017 